\title{
Determinantes das exportações brasileiras de mamão à luz do modelo gravitacional
}

\author{
Determinants of Brazilian papaya export considering the \\ gravitational model \\ Erivelton de Souza Nunes ${ }^{1}$ (D), Ahmad Saeed Khan ${ }^{2,3}$ (D), Eliane Pinheiro de Sousa ${ }^{2,3}$ (D), \\ Francisco José Silva Tabosa' ${ }^{1}$

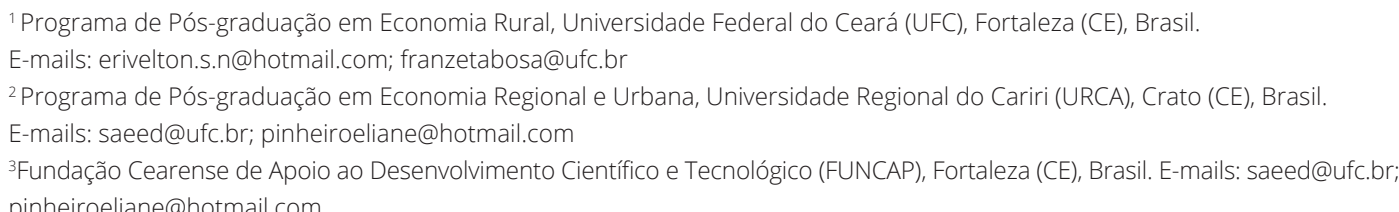 \\ pinheiroeliane@hotmail.com
}

\begin{abstract}
Como citar: Nunes, E. S., Khan, A. S., Sousa, E. P., \& Tabosa, F. J. S. (2021). Determinantes das exportações brasileiras de mamão à luz do modelo gravitacional. Revista de Economia e Sociologia Rural, 59(4), e222983. https://doi.
\end{abstract} org/10.1590/1806-9479.2021.222983

Resumo: O presente estudo se propõe a analisar os determinantes das exportações brasileiras de mamão, considerando países da Europa, da América do Sul e da América do Norte que representam quase 99\% do total de exportações da referida fruta de 2002 a 2017. Para tanto, empregou-se o modelo gravitacional, que consiste na aplicação da metodologia de dados em painel, e consideraram-se variáveis as rendas per capita do Brasil e dos países importadores, distância, taxa de câmbio, índice de liberdade comercial, preços internacionais e variáveis binárias, que correspondem ao bloco econômico do qual o país importador faz parte, e a presença de litoral. Os resultados mostraram que as exportações do mamão brasileiro são explicadas diretamente pelo produto do tamanho econômico de seus parceiros comerciais e inversa e proporcionalmente à distância que os separam do Brasil. Destaca-se, ainda, a relação direta desse fluxo comercial com os preços internacionais, bem como com a taxa de câmbio. Ademais, evidenciam-se desempenhos inferiores de países do Mercosul e do Nafta nas exportações do mamão brasileiro, quando comparados aos de países europeus.

Palavras-chave: modelo gravitacional; comércio internacional; mamão.

\begin{abstract}
The present study aims to analyze the determinants of Brazilian papaya exports, considering countries in Europe, South America, and North America that represent almost 99\% of the total exports of the fruit from 2002 to 2017. For that, the gravitational model was used, which consists of the application of the panel data methodology, and the per capita incomes of Brazil and the variables importing countries, distance, exchange rate, commercial freedom index, international prices were considered, and the binary variables, which correspond to the economic bloc of which the importing country is a part, and the presence of the coast., The results showed that Brazilian papaya exports are explained directly by the product of the economic size of its commercial partners and inversely proportional to the distance that separates them from Brazil. It is also worth mentioning the existence of a direct relationship between this trade flow and international prices, as well as the exchange rate. In addition, lower performances from MERCOSUR and NAFTA countries are observed in Brazilian papaya exports, when compared to European bloc countries.
\end{abstract}

Keywords: Gravity model. International trade. Papaya.

\section{Introdução}

De acordo com Zanchi et al. (2013), as condições climáticas e a vasta dimensão territorial do Brasil privilegiam o país em termos de exploração da atividade agropecuária. Nesse sentido, a produção de frutas insere-se como boa alternativa ao reduzido dinamismo econômico de determinadas regiões do país, sendo uma importante maneira de oferecer emprego e renda, 
bem como de contribuir para que o país tenha importância no comércio internacional, haja vista que esse segmento de mercado vem se tornando cada vez mais atrativo.

Fonseca et al. (2010) expressam que o crescimento do comércio internacional de frutas relaciona-se à tendência de elevação do nível global de renda, com transformações nos hábitos de consumo, em que é propagada amplamente a relevância do consumo de alimentos saudáveis. Jaime et al. (2009) reforçam a importância do consumo, afirmando que a promoção do consumo de frutas é determinada pela Organização Mundial da Saúde (OMS) como prioridade nos programas e políticas voltados à nutrição e à alimentação. Além desses fatores, Tomich (1999) sinaliza que o consumo de frutas reflete redução nas doenças cardiovasculares e de câncer.

Nesse âmbito, está inserido o cultivo do mamão que tem ocupado papel relevante na pauta de exportações brasileiras. De acordo com Serrano \& Cattaneo (2010), o mamão (Carica papaya $L$.), pertencente à família Caricaceae, é considerado uma das frutas mais cultivadas e consumidas em regiões tropicais e subtropicais do mundo, sendo importante fornecedor de cálcio, provitamina A e vitamina C (ácido ascórbico). Hardisson et al. (2001) e Wall (2006) indicam que o mamão e seus derivados possuem uma rica fonte de minerais - magnésio, potássio, boro e cobre. Conforme Nakasone \& Paull (1998), Ahmed et al. (2002) e Tansakul et al. (2012), pode ser consumido in natura ou processado de diferentes formas, como em fatias desidratadas, saladas, sucos, néctares, sorvetes, purês, geleias ou frutas secas. Anibijuwon \& Udeze (2009) complementam exprimindo que diferentes partes do mamão, como frutos, sementes, casca, folhas, raízes e látex, têm sido usadas para tratar várias doenças, como icterícia, dificuldades estomacais, dengue, micose, lombrigas, problemas urinários, atividade anti-hemofílica, obesidade e hipertensão arterial, trazendo, assim, benefícios nutricionais e medicinais.

Conforme dados da Faostat (Food and Agriculture Organization of the United Nations, 2018), o mamão é produzido comercialmente em cerca de 34 países, de modo que, ao considerar 2013, o Brasil ocupou um posto de elevado destaque, na segunda colocação, com valor de produção equivalente a aproximadamente 817 milhões de dólares, atrás apenas da Índia, que obteve, nesse mesmo ano, cerca de 2 bilhões, em termos de valor da produção. Além disso, o Brasil também se destaca como o segundo no ranque mundial de exportações desse produto, atrás apenas do México. Desse modo, é notória a relevância do Brasil no panorama internacional, tanto da produção como da exportação do mamão. A exportação desse produto analisado representa um relevante vetor de crescimento econômico e demanda por emprego em regiões de baixa renda no país.

Segundo dados do Brasil (2018), de 2002 a 2017, aproximadamente 83\% das exportações brasileiras de mamão foram direcionadas à Europa, enquanto o restante se distribuiu entre alguns países dos demais continentes, com destaque para os Estados Unidos, que teve alta representatividade, equivalente a $13,11 \%$.

Zanchi (2010) acentua que, apesar da importância da fruticultura como instrumento gerador de divisas, sua importância ainda é baixa comparada ao seu potencial. Além disso, Faria et al. (2008) indicam que, em razão das exigências cada vez maiores quanto às medidas técnicas e fitossanitárias ligadas, especialmente, às dificuldades de colheita do mamão, bem como de crescentes custos de produção, de embalagem e logística para atender a tais exigências, são cada vez maiores os custos de transação gerados pelos investimentos dos produtores em determinados ativos, sendo evidentes as incertezas originadas das dificuldades de comercialização entre produtores nacionais e importadores.

Por outro lado, a logística é considerada por Zanchi et al. (2013) o grande obstáculo à competitividade, à modernização e ao avanço do setor frutícola brasileiro. As precárias condições de produção e comercialização desencorajam diversos produtores e, assim, as relações 
comerciais de frutas in natura, especialmente direcionadas ao setor externo, não alcançam a escala necessária. Soma-se isso ao elevado nível de perecibilidade, tornando necessário o rápido deslocamento das frutas em direção aos consumidores, a fim de conservar suas melhores características, ou que estas sejam armazenadas em adequadas condições climáticas. Tal integração é apontada por Fackler \& Goodwin (2001) como um fator que possibilita aos agentes econômicos mais competitividade no comércio internacional, haja vista que estes têm mais possibilidades de crescimento.

Vitti (2009) salienta, no entanto, que é inegável o potencial da fruticultura nacional, que necessita de mais dinamização em termos de exportação, já que consiste em um dos segmentos mais qualificados para produção e, por consequência, ter mais importância na geração de empregos e divisas. Ademais, o Brasil é privilegiado em termos de posição geográfica quando comparado a outros países, tendo amplo litoral e clima predominantemente tropical.

Assim, dados o crescente dinamismo do mercado internacional de frutas e as dificuldades brasileiras em se inserir nesse cenário com competitividade, pela problemática antes mencionada, torna-se fundamental analisar os determinantes das exportações frutícolas no país. Diante da crescente importância do mamão, tanto em termos nutritivos como produto gerador de divisas, além de sua maior produtividade, entre as principais frutas brasileiras, torna-se relevante analisar os determinantes das exportações brasileiras de mamão, por meio da estimação de uma equação da oferta de exportação do referido produto à luz do modelo gravitacional, haja vista que, segundo Soares \& Silva (2011), tal procedimento é fundamental para o planejamento da produção, comercialização, previsão e formulação de políticas públicas para o setor, refletindo-se em efeitos positivos sobre as exportações dessa fruta nacional. Além disso, procura-se contribuir em termos metodológicos no sentido de adotar o poisson pseudo-maximum-likelihood (PPML) ao setor frutícola, haja vista que essa estimativa tem bom desempenho tanto da heterocedasticidade quanto de fluxos comerciais nulos, o que é o caso do mercado exportador do mamão brasileiro.

\section{Referencial teórico}

Esta seção traz as principais evidências que dão sustentação teórica ao modelo gravitacional e são expostos alguns estudos que aplicaram tal metodologia sob diferentes abordagens, a fim de contextualizar o emprego do modelo econométrico mencionado no estudo em questão.

\subsection{Modelo gravitacional: evidências teóricas e aplicações empíricas}

Segundo Silva (2017), os primeiros trabalhos a aplicarem a lógica do modelo gravitacional ao comércio internacional como forma de explicar as relações comerciais entre países foram os de Tinbergen (1962) e Poyhonen (1963), tendo sido melhorado por Linnemann (1966).

O propósito inicial de Tinbergen (1962) era avaliar os grupos de fatores que mais explicariam a magnitude dos fluxos comerciais entre os países. Tais grupos se distribuíam de três maneiras distintas. O primeiro era composto de fatores associados à oferta potencial total do país exportador; o segundo dizia respeito aos fatores referentes à capacidade potencial de demanda dos países importadores. Assim, esses dois fatores representavam, respectivamente, o PIB dos países exportadores e importadores. Por fim, o terceiro correspondia à resistência ao comércio, que poderia ser natural ou artificial. A barreira natural consistia em dificuldades criadas ao comércio como resultado das imposições da própria natureza, a exemplo dos custos e tempo de transporte. Já a barreira artificial era instituída pelo governo. Posteriormente, Linnemann 
(1966) incluiu, nas análises de fluxos comerciais entre países exportadores e importadores, o tamanho populacional, com vistas a captar o efeito das economias de escala (Cardoso et al., 2016; Porto \& Canuto, 2004).

Segundo Kristjánsdóttir (2005), o modelo gravitacional baseia-se no conceito de gravidade, originado da Física, e refere-se à lei de gravidade, de Newton. Abidin et al. (2016) e Bampi (2017) lembram que a referida lei sustenta a existência de uma força de atração entre dois corpos, que é diretamente proporcional ao produto de suas massas e inversamente proporcional ao quadrado da distância entre elas, podendo ser representada na Expressão 1:

$\mathrm{F}=\mathrm{G} \frac{\mathrm{M}_{\mathrm{i}} \mathrm{M}_{j}}{\mathrm{D}^{2}}$

em que: $\mathrm{F}$ representa a força gravitacional; G consiste na constante gravitacional; $\mathrm{M}_{\mathrm{i}} \mathrm{M}_{\mathrm{j}}$ trata-se das massas dos corpos; D corresponde à distância.

A estrutura lógica do modelo gravitacional parte da ideia de que, dado que o PIB de determinado país corresponde ao valor dos bens e serviços por ele comercializados, este será, por definição, equivalente à despesa total em bens e serviços que ele produz (Krugman \& Obstfeld, 2010). Com efeito, Prates e Pereira (2015) indicam que, embora o PIB represente uma medida da renda da economia, seu valor não reflete o total da participação no comércio, uma vez que diversos países despendem parcela majoritária de sua renda internamente, e existem alguns fatores que dificultam o comércio internacional. Logo, constata-se que o fluxo comercial entre os países representa apenas parcela do PIB deles.

O ajuste da lei gravitacional de Isaac Newton às relações comerciais entre os países propõe que o comércio internacional seja diretamente proporcional às suas rendas, que representam as massas, e inversamente proporcional ao distanciamento geográfico entre eles. Desse modo, dado que as transações comerciais são relacionadas ao tamanho econômico dos países, economias mais dinamizadas tendem a registrar níveis mais intensos de comércio, enquanto a distância é expressa como um empecilho, uma vez que quanto maior o distanciamento geográfico entre os países, menores tendem a ser as suas relações comerciais, já que maiores custos de transações e demais fatores associados são evidentes nesse caso (Krugman \& Obstfeld, 2010; Gräf \& Azevedo, 2013).

Conforme a literatura que versa sobre o comércio internacional, as aplicações iniciais relacionadas ao uso do modelo gravitacional ocorreram em meados da década de 1960 . No entanto, durante um grande espaço temporal, procurou-se encontrar um embasamento teórico adequado para o modelo, ante as distintas hipóteses elaboradas sobre o comércio internacional. Desse modo, a aplicação da equação gravitacional era expressa apenas pela sua adequação às aplicações empíricas de explicação dos fluxos comerciais entre países (Fratianni, 2009).

Nesse sentido, os estudos iniciais não possuíam fundamentos teóricos que pudessem dar sustentação ao modelo especificado, cujos resultados eram obtidos de modo intuitivo, sendo essa, conforme Cardoso et al. (2016), a grande deficiência do modelo gravitacional tradicional durante a década de 1960, muito embora tais estudos tenham fornecido as variáveis mais importantes e suas proxiesúteis na literatura recente que busca determinar o comércio bilateral internacional. Neste sentido, Porto \& Canuto (2004) sinalizam que a forma original da equação gravitacional tradicional é expressa pela Equação 2:

$\mathrm{X}_{\mathrm{ij}}=\alpha_{0}\left(\mathrm{Y}_{\mathrm{i}}\right)^{\alpha_{1}}\left(\mathrm{Y}_{\mathrm{j}}\right)^{\alpha_{2}}\left(\mathrm{~N}_{\mathrm{i}}\right)^{\alpha_{3}}\left(\mathrm{~N}_{\mathrm{j}}\right)^{\alpha_{4}}\left(\text { Dist }_{\mathrm{ij}}\right)^{\alpha_{5}} \mathrm{e}^{\left(\mathrm{Pref}^{\alpha_{6}}\right.}\left(\mathrm{e}_{\mathrm{ij}}\right)$ 
em que: $X_{\mathrm{ij}}$ representa o valor nominal das exportações do país i para o país ${ }_{\mathrm{j}} ; \mathrm{Y}_{\mathrm{i}}$ corresponde ao valor nominal do PIB do país $\mathrm{i} ; \mathrm{Y}_{\mathrm{j}}$ diz respeito ao valor nominal do PIB do país $\mathrm{j} ; \mathrm{N}_{\mathrm{i}}$ e $\mathrm{N}_{\mathrm{j}}$ referem-se às populações dos países $i$ e $j$, respectivamente; Distij relaciona-se à distância geográfica existente entre os países que exercem a relação comercial; Pref consiste em uma variável binária, que assume valor 1 quando os dois países fazem parte de uma determinada área de comércio preferencial e 0 , caso contrário; $\mathrm{e}_{\mathrm{ij}}$ que se trata do termo de erro estocástico e que contempla outras possíveis variáveis que possam gerar influências no modelo, mas que não estão sendo consideradas. Já os coeficientes de $\alpha_{0}$ a $\alpha_{6}$ devem ser estimados por meio de regressões.

Como salientam Almeida et al. (2011), os escritos de Anderson (1979) e Bergstrand (1985, 1990) foram os primeiros a dar contribuições formais que pudessem sustentar, teoricamente, a equação gravitacional. O primeiro estudo concentrou-se na aplicação do modelo gravitacional exclusivamente para commodities e apresentou uma abordagem teórica, com base nas preferências da função do tipo Cobb-Douglas e elasticidade de substituição constante (CES). As suposições de sua abordagem sugerem que existe homogeneidade perfeita entre as regiões e ocorre diferenciação de produtos por países de origem. Considera-se, inicialmente, em seu sistema, que cada país produz um produto específico comercializável e, posteriormente, adiciona outro produto não comercializável ao modelo. Como principais resultados, verificaram-se que diversos produtos passam a ser transacionados, diferenciando-se apenas pelo local de onde se originam e pela distância, que se relaciona, de forma inversa, ao fluxo de comércio e, assim, o modelo de gravidade poderia ser obtido de propriedades de sistemas de dispêndio. Kristjánsdóttir (2005), no entanto, afirma que tais conclusões são limitadas, na medida em que são considerados, exclusivamente, países com estrutura e preferências semelhantes.

Já os estudos de Bergstrand (1985, 1990), conforme Mata \& Freitas (2008), assumem as preferências do CES e testam a hipótese de diferenciação de produtos, para fornecer evidências empíricas de que as variáveis, a exemplo do preço e da taxa de câmbio, influenciam, de maneira significativa, o fluxo agregado de comércio. Para esse autor, a equação gravitacional é uma modalidade reduzida de um subsistema parcial de um modelo de equilíbrio geral com produtos distintos em termos nacionais.

Consoante Silva \& Almeida (2009) e Pereira \& Almeida (2014), as contribuições teóricas concernentes ao modelo gravitacional foram reforçadas pelos estudos de Deardorff (1998), que exibiu uma possibilidade de derivação da equação gravitacional com suporte no modelo de Heckscher-Ohlin e considera um modelo com produtos homogêneos e um mercado sob concorrência perfeita; Anderson \& Wincoop (2003) sugerem a possibilidade de derivação da referida equação por meio de uma função de utilidade na forma de elasticidade de substituição constante (CES) sujeita a uma restrição orçamentária, relacionada com condições de equilíbrio de mercado.

Os estudos de Anderson \& Wincoop $(2003,2004)$ são considerados, de acordo com Souza \& Burnquist (2011), Pereira \& Almeida (2014) e Arevalo et al. (2016), uma abordagem-padrão na literatura de comércio internacional recente e mostram a importância dos custos comerciais, sinalizando que não são dependentes exclusivamente da distância existente entre os dois países. Portanto, devem ser incorporados aos custos comerciais aspectos como partilha de fronteiras, presença de acordos e barreiras comerciais. Sugerem, ainda, que se incorporem ao modelo fatores de custos que procurem captar o efeito dos fluxos comerciais bilaterais, como medidas técnicas e o idioma praticado.

Conforme Souza \& Burnquist (2011), Pereira \& Almeida (2014) e Arevalo et al. (2016), a especificação do modelo de Anderson \& Wincoop $(2003,2004)$ pode ser representada pela Expressão 3: 
$X_{i j}^{k}=\frac{E_{j}^{k} Y_{i}^{k}}{Y^{k}}\left(\frac{t_{i j}^{k}}{P_{j}^{k} \prod_{i}^{k}}\right)^{1-\sigma_{k}}$

em que: $X_{\mathrm{ij}}^{\mathrm{k}}$ refere-se às trocas comerciais do segmento $\mathrm{k}$ que ocorrem entre o país i e o país ${ }_{j}$; $\mathrm{E}_{\mathrm{j}}^{\mathrm{k}}$ reflete os gastos do país ${ }_{\mathrm{j}}$ em produtos do segmento $\mathrm{k}$; $\mathrm{Y}_{\mathrm{i}}^{\mathrm{k}}$ e $\mathrm{Y}^{\mathrm{k}}$ indicam, respectivamente, a quantidade produzida de mercadorias do segmento $\mathrm{k}$ no país ie a produção agregada internacional de tais mercadorias; $\prod_{i}^{k}$ corresponde aos índices de preços representativos da resistência multilateral da relação comercial; $t_{\mathrm{ij}}^{\mathrm{k}}$ indica as despesas correntes ao se exportar $\mathrm{k}$; $\sigma_{\mathrm{k}}$ diz respeito à elasticidade de substituição entre os produtos.

Com vistas a evidenciar a existência de uma fundamentação teórica para a equação gravitacional, Feenstra et al. (2001) mostram que o modelo pode ser derivado de várias teorias, desde modelos com produtos heterogêneos e sob um mercado de concorrência imperfeita, como os estudos de Krugman (1980) e Helpman \& Krugman (1985), como na ótica de Armington, ou seja, considerando a distinção dos produtos de acordo com o país de onde se origina. Esses autores assinalam que o modelo gravitacional também pode ser obtido por meio de um modelo de dumping recíproco, tendo em vista a presença ou ausência de barreiras comerciais. Salientam, ainda, que diferentes teorias levam a efeitos distintos sobre o mercado doméstico, que são relevantes.

Farias \& Hidalgo (2012) ressaltam que a consistência nos resultados obtidos por meio da aplicação do modelo gravitacional ao comércio internacional motivou a busca por fundamentos que pudessem dar suporte teórico às evidências empíricas. Além disso, lembram que, embora o método tenha se mostrado adequado aos fluxos comerciais, também tem sido aplicado em diversos outros exercícios empíricos. Nesse sentido, podem ser citados os estudos de Helliwell (1997), Egger \& Pfaffermayr (2004) e Zhu \& Yang (2008), que realizaram análises dos fluxos migratórios, fluxos de investimentos estrangeiros diretos e contágios em crises financeiras, respectivamente.

Segundo a literatura econômica, os primeiros que adotaram o modelo gravitacional no Brasil foram Hidalgo e Vergolino (1998), que procuraram analisar o fluxo comercial do Nordeste para as demais regiões brasileiras, bem como para o mercado externo. Posteriormente, podem ser citados os estudos de Leusin Júnior \& Azevedo (2009), que estudaram o efeito-fronteira do Brasil e de suas regiões; Farias \& Hidalgo (2012), que avaliaram o comportamento dos comércios interestadual e internacional das regiões brasileiras para o período posterior à abertura comercial do país; Paula \& Miranda (2017), que realizaram uma investigação acerca dos fatores determinantes do padrão de comércio entre países que compõem o BRICS.

Segundo a literatura econômica, considerando os fluxos comerciais de determinados produtos agrícolas com amparo na utilização do modelo gravitacional, destacam-se os estudos de Arevalo et al. (2016), Silva (2015), Zanchi et al. (2013) e Mata \& Freitas (2008), que analisaram, respectivamente, fatores associados à oferta de exportação de café no Brasil, Colômbia e Peru; os principais determinantes que influenciam o desempenho exportador da manga e da uva; o desempenho das exportações de frutas brasileiras in natura; os determinantes das exportações de produtos agropecuários no Brasil.

\section{Caracterização da produção e do comércio do mamão brasileiro}

Segundo Fachinello et al. (2011), a fruticultura encontra-se presente em todos os estados brasileiros e, como atividade econômica, tem forte relevância na geração de empregos diretos e indiretos. De acordo com Kist et al. (2018), o setor frutícola representou, em 2019, aproximadamente 6 milhões de empregos diretos, o que equivale a $27 \%$ da produção agrícola nacional, o que comprova sua importância na geração de empregos. Além disso, considerando 
as inúmeras cadeias produtivas, o setor apresenta movimentos financeiros superiores a $\mathrm{R} \$ 40$ bilhões anuais.

Os dados obtidos do IBGE (Instituto Brasileiro de Geografia e Estatística, 2020), apresentados na Tabela 1, consideram as dez principais frutas de cultivo permanente de 2002 a 2017 e demonstram que, em termos de acumulação da quantidade produzida e valor da produção, o mamão destaca-se como a quarta fruta mais relevante, atrás apenas da laranja, banana e coco-da-baía, em termos de quantidade, e da laranja, banana e uva, em termos de valor produzido. Além disso, nota-se que o mamão foi a fruta que apresentou a menor área colhida acumulada no período (538 hectares), de modo que, relacionando a quantidade produzida acumulada com a área colhida acumulada do período, tem registrado a maior produtividade ante as demais frutas.

Tabela 1. Quantidade produzida, valor da produção e área colhida das principais frutas brasileiras de 2002 a 2017

\begin{tabular}{|c|c|c|c|c|c|c|c|c|c|}
\hline \multirow{3}{*}{ Produtos } & \multirow{2}{*}{\multicolumn{3}{|c|}{$\begin{array}{c}\text { Quantidade produzida } \\
\text { (em toneladas) }\end{array}$}} & \multirow{2}{*}{\multicolumn{3}{|c|}{$\frac{\text { Valor da produção }}{\text { (em mil reais) }}$}} & \multirow{2}{*}{\multicolumn{3}{|c|}{$\frac{\text { Área colhida }}{\text { (em hectares) }}$}} \\
\hline & & & & & & & & & \\
\hline & 2002 & 2017 & Acumulado & 2002 & 2017 & Acumulado & 2002 & 2017 & Acumulado \\
\hline Laranja & 18530,58 & 17492,88 & 286720,16 & 3866,19 & 8579,03 & 86877,37 & 828843,00 & 632939 & 12220876 \\
\hline Banana & 6689,18 & 6584,97 & 109730,03 & 2111,12 & 7929,84 & 66042,41 & 502939,00 & 461365 & 7846797 \\
\hline Uva & 1148,65 & 1743,43 & 21768,92 & 1009,16 & 3195,48 & 29721,75 & 66300,00 & 75734 & 1229077 \\
\hline Mamão & 1597,70 & 1058,49 & 26157,12 & 502,19 & 929,55 & 16579,56 & 35626,00 & 26675 & 538756 \\
\hline Maçã & 857,39 & 1307,64 & 18051,04 & 466,35 & 1625,77 & 15269,04 & 31519,00 & 33328 & 575950 \\
\hline Coco-da-baía & 1928,24 & 1473,43 & 30768,10 & 504,28 & 1075,18 & 13091,03 & 276598,00 & 209406 & 4273814 \\
\hline Manga & 849,75 & 1089,88 & 17638,86 & 313,61 & 999,64 & 10577,26 & 66676,00 & 64025 & 1130529 \\
\hline Maracujá & 478,65 & 548,09 & 10766,55 & 219,93 & 855,30 & 10096,87 & 34778,00 & 41067 & 762864 \\
\hline Tangerina & 1262,74 & 967,14 & 17583,26 & 303,12 & 835,63 & 9124,72 & 64609,00 & 50144 & 894618 \\
\hline Limão & 984,55 & 1293,77 & 17233,02 & 219,49 & 1233,57 & 8875,23 & 50125,00 & 48162 & 744283 \\
\hline
\end{tabular}

Fonte: elaborada pelos autores com base nos dados de IBGE (Instituto Brasileiro de Geografia e Estatística, 2020).

A Tabela 2, por sua vez, apresenta informações para os seis principais frutos da pauta de exportação do setor de 2002 a 2017, sendo o mamão o sexto colocado, tanto em termos de valor acumulado quanto em termos de quantidade acumulada, evidenciando a importância desse produto gerador de divisas e relevância na pauta de exportação frutícola brasileira.

Tabela 2. Principais frutas brasileiras exportadas no período de 2002 a 2017

\begin{tabular}{|c|c|c|c|c|c|c|}
\hline \multirow{2}{*}{ Frutas } & \multicolumn{3}{|c|}{ Valor exportado (em mil US\$) } & \multicolumn{3}{|c|}{$\begin{array}{c}\text { Quantidade exportada (em } \\
\text { toneladas) }\end{array}$} \\
\hline & 2002 & 2017 & $\begin{array}{c}\text { Valor } \\
\text { acumulado }\end{array}$ & 2002 & 2017 & $\begin{array}{l}\text { Quantidade } \\
\text { acumulada }\end{array}$ \\
\hline Melões frescos & 37778,01 & 162916,22 & 1890517,37 & 98689,91 & 233652,66 & 2717585,53 \\
\hline $\begin{array}{l}\text { Mangas frescas ou } \\
\text { secas }\end{array}$ & 0,00 & 205111,21 & 1807878,33 & 0,00 & 179601,17 & 1667690,89 \\
\hline Uvas frescas & 33748,58 & 96207,30 & 1620384,08 & 65927,28 & 55436,65 & 1230766,31 \\
\hline $\begin{array}{l}\text { Limões e limas } \\
\text { frescos ou secos }\end{array}$ & 7523,25 & 82088,71 & 832543,36 & 15982,81 & 92392,87 & 930030,82 \\
\hline Maçãs frescas & 31403,19 & 41883,83 & 760410,55 & 26345,50 & 44493,44 & 744142,73 \\
\hline $\begin{array}{l}\text { Mamões (papaias) } \\
\text { frescos }\end{array}$ & 21617,36 & 41350,01 & 573617,29 & 40373,68 & 32297,59 & 586160,37 \\
\hline
\end{tabular}

Fonte: elaborada pelos autores com base nos dados da Faostat (Food and Agriculture Organization of the United Nations, 2018). 
Em termos de importância do Brasil no comércio internacional de frutas, dados da Faostat (Food and Agriculture Organization of the United Nations, 2018) revelam que, considerando 0 valor acumulado em dólares para o período de 2002 a 2017, para as dez frutas mais exportadas pelo Brasil (melão, manga, uva, limão, maçã, mamão, melancia, laranja, banana e figo), o país tem se apresentado pouco competitivo, figurando apenas como $17^{\circ}$ maior exportador no comércio internacional (US\$ 8,9 bilhões).

No entanto, os dados da Faostat (Food and Agriculture Organization of the United Nations, 2018), apresentados na Tabela 3, também mostram que, especificamente em se tratando do mamão, o país tem demonstrado alta participação no comércio internacional, uma vez que, ao longo do período de 2002 a 2017, proporcionou a geração de cerca de US\$589 milhões, por meio da exportação de aproximadamente 524 toneladas, sendo o segundo em exportação desse fruto no comércio internacional, atrás apenas do México, com uma quantidade acumulada exportada e valor acumulado de, respectivamente, pouco mais de US\$1 bilhão e 1,8 milhão de toneladas.

Tabela 3. Principais exportadores de mamão no comércio internacional de 2002 a 2017

\begin{tabular}{|c|c|c|c|c|c|c|}
\hline \multirow{2}{*}{ Países } & \multicolumn{4}{|c|}{ Valor exportado (em mil US\$) } & \multicolumn{2}{|c|}{$\begin{array}{c}\text { Quantidade exportada } \\
\text { (em toneladas) }\end{array}$} \\
\hline & 2002 & 2017 & $\begin{array}{c}\text { Valor } \\
\text { acumulado }\end{array}$ & 2002 & 2017 & $\begin{array}{l}\text { Quantidade } \\
\text { acumulada }\end{array}$ \\
\hline México & 30080 & 80014 & 1045102 & 68558 & 162867 & 1802520 \\
\hline Brasil & 21624 & 41350 & 570955 & 28541 & 39117 & 524604 \\
\hline Estados Unidos & 13604 & 23519 & 299148 & 7106 & 14226 & 167957 \\
\hline Holanda & 6855 & 25605 & 282847 & 3362 & 8597 & 121102 \\
\hline Malásia & 26247 & 9151 & 203733 & 60892 & 25457 & 550415 \\
\hline Belize & 7940 & 1107 & 164051 & 11307 & 1699 & 345578 \\
\hline Guatemala & 726 & 25402 & 115176 & 2475 & 60685 & 292396 \\
\hline Índia & 979 & 6925 & 67891 & 3452 & 11508 & 180128 \\
\hline China & 3170 & 14792 & 66295 & 5120 & 8735 & 91865 \\
\hline Filipinas & 5310 & 2512 & 57467 & 4311 & 2176 & 48152 \\
\hline
\end{tabular}

Fonte: elaborada pelos autores com base nos dados da Faostat (Food and Agriculture Organization of the United Nations, 2018).

Em termos de desagregação nacional, os dados fornecidos por Brasil (2018), apresentados na Figura 1, evidenciam que, tendo em vista o valor acumulado das exportações de 2002 a 2017, tem-se que os principais estados exportadores do fruto no país são Espírito Santo, Rio Grande do Norte, Bahia e Paraíba, que, a partir do total exportado pelo país no período, representam aproximadamente $99 \%$, sendo os principais exportadores de mamão ao longo desse período.

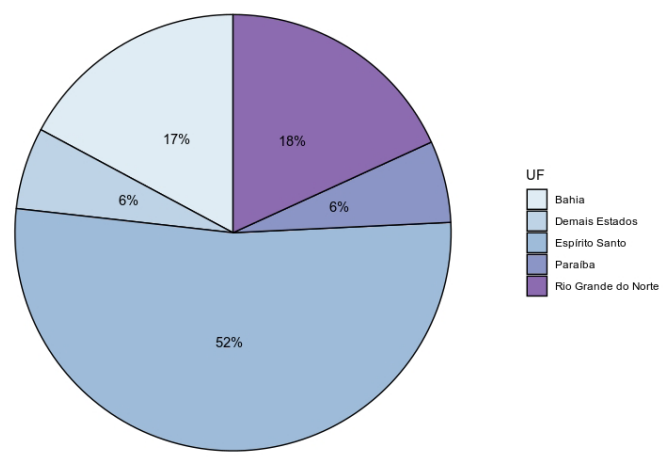

Figura 1. Principais estados exportadores do mamão brasileiro de 2002 a 2017. Fonte: elaborada pelos autores com base nos dados de Brasil (2018). 
Ademais, convém destacar que, conforme a Figura 2, elaborada de dados de Brasil (2018), observa-se que, de 2002 a 2017, Países Baixos (Holanda), Portugal, Reino Unido, Espanha, Alemanha, França e Itália, que compõem a União Europeia, absorveram 78\% das exportações do mamão brasileiro, sendo o bloco mais representativo, enquanto Estados Unidos e Canadá, pertencentes ao Tratado Norte-Americano de Livre Comércio (Nafta), foram responsáveis por aproximadamente $15,57 \%$ das exportações. A Suíça, que integra a Associação Europeia de Comércio Livre (EFTA), respondeu por 4,57\% das exportações, enquanto os demais países respondem por participação singela de 1,34\%.

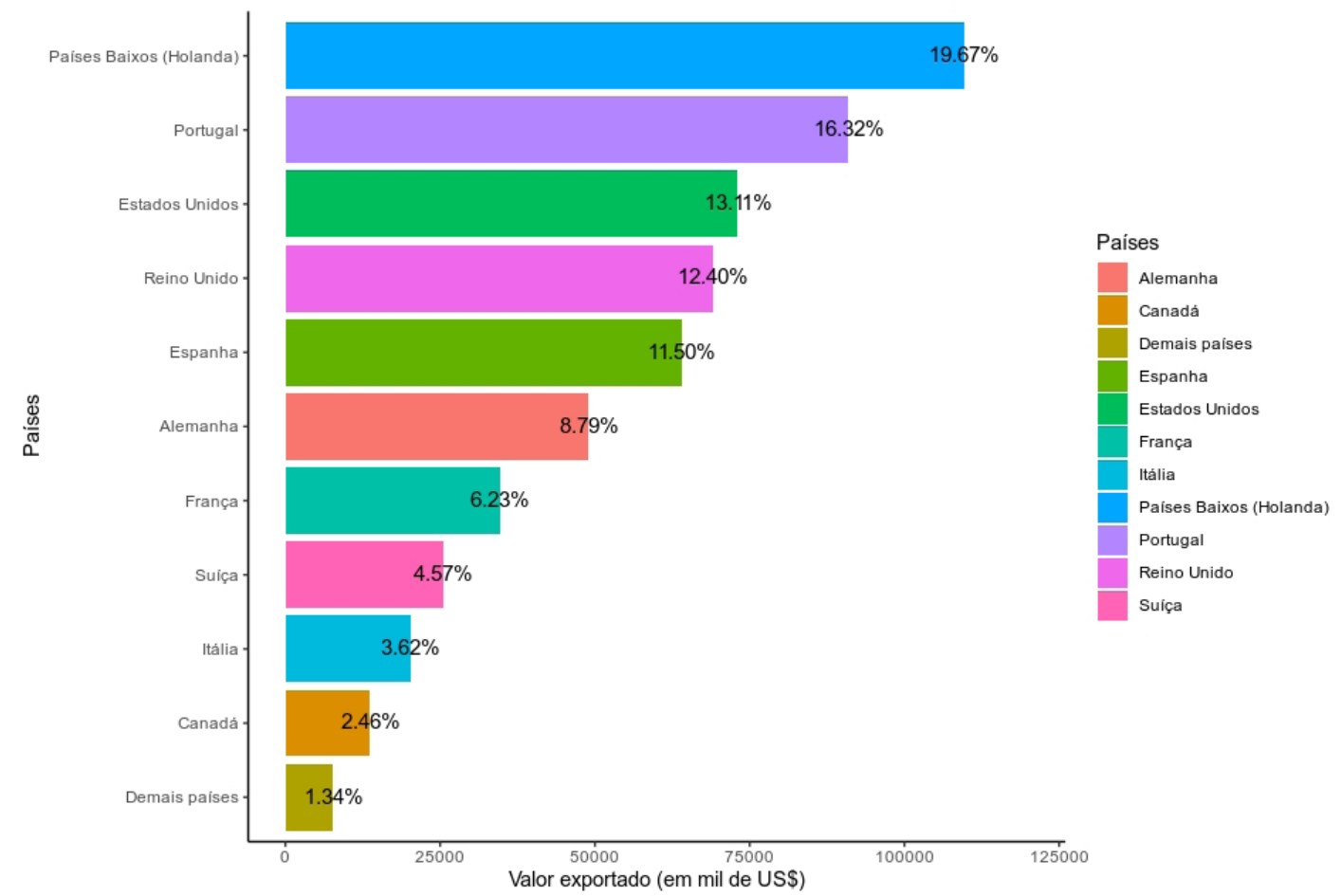

Figura 2. Principais importadores do mamão brasileiro de 2002 a 2017. Fonte: elaborada pelos autores com base nos dados de Brasil (2018).

Tais resultados evidenciam a relevância da União Europeia como principal mercado de destino das exportações brasileiras de mamão, portanto a presente análise considerou tal bloco referência na análise econométrica. Entre os demais países (1,34\%), destacam-se a abertura de novos mercados, como o da Rússia, em 2014, e o dos Emirados Árabes Unidos, a partir de 2013.

\section{Metodologia}

Nesta seção, mostram-se a base de dados e o modelo econométrico adotado na pesquisa. Utilizou-se o modelo gravitacional, estimado por meio de um painel de dados balanceado. Consideraram-se os seguintes métodos: dados empilhados ou pooled, EF, EA e PPML, dada a sua maior robustez.

\subsection{Fontes de dados}

No que concerne à verificação dos determinantes das exportações do mamão brasileiro, tem-se que os dados para as exportações da fruta foram coletados no sistema de consultas 
e extração de dados do comércio exterior brasileiro (Comex Stat), do Brasil, Ministério do Desenvolvimento, Indústria e Comércio Exterior (MDIC). Os indicadores referentes ao PIB brasileiro foram obtidos por meio do Instituto Brasileiro de Geografia e Estatística (IBGE). Já o produto interno bruto (PIB) dos países importadores foi tomado do Banco Mundial. A distância foi coletada do Centro de Pesquisa Francês no Âmbito da Economia Internacional (Centre d'Estudes Prospectives et d'Intertionales Distance, 2021), que emprega o critério de cidades principais, listadas na Tabela $1 \mathrm{~A}$ do Apêndice, em que a distância entre os parceiros comerciais foi mensurada em termos de quilometragem, pelas coordenadas geográficas de suas principais cidades, ou seja, latitude e longitude.

O índice de liberdade comercial (ILC) foi obtido da Heritage Foundation, conforme sugerido por Arevalo et al. (2016). As informações referentes à taxa de câmbio e aos preços internacionais do mamão foram obtidas por meio das estatísticas da Food and Agriculture Organization of the United Nations (Faostat). No caso da taxa de câmbio, consideraram-se as taxas de câmbio dos principais países importadores do mamão brasileiro em relação ao real, convertidas em dólar. Quanto aos preços internacionais, considerou-se o preço, em dólar, do quilograma da fruta. Ademais, foram construídas variáveis binárias, que indicam o bloco econômico do qual o país importador faz parte e se esse país tem litoral, conforme o estudo de Silva (2015). Ressalta-se que o período considerado é de 2002 a 2017, dada a disponibilidade de dados para esses anos.

Cabe destacar o fato de que o ILC foi retirado da Heritage Foundation, seguindo os estudos de Arevalo et al. (2016) e Aguiar (2018), de modo que esse indicador varia de 0 a 100, expressando liberdade restrita (0 a 49,9), predominantemente restrita (50 a 59,9), parcialmente livre (60 a 69,9), predominante livre (70 a 79,9) e completamente livre (80 a 100).

Salienta-se que foram considerados 21 países: Argentina, Áustria, Bélgica, Canadá, Dinamarca, Etiópia, França, Alemanha, Itália, Luxemburgo, Holanda, Polônia, Portugal, Rússia, Arábia Saudita, Espanha, Suíça, Emirados Árabes Unidos, Reino Unido, Estados Unidos e Uruguai, que representam $99 \%$ do destino das exportações brasileiras de mamão, tendo sido considerado o período de 2002 a 2017, totalizando 336 observações. Ademais, realizou-se a deflação de todas as variáveis monetárias pelo índice de preços ao consumidor (IPC) norte-americano, a fim de captar toda a inflação não desprezível do período.

\subsection{Modelo gravitacional}

A literatura que versa acerca da aplicação do modelo gravitacional sobre diferentes aspectos do comércio internacional assume várias modalidades. No presente estudo, optou-se por adotar o modelo chamado one way effect, para isolar potenciais efeitos fortes associados à demanda pelo mamão brasileiro pelos países importadores. Nesse sentido, os métodos mais comumente adotados são os de mínimos quadrados ordinários pooled, que se referem aos dados empilhados, os de efeitos fixos (EF) e efeitos aleatórios (EA), obtidos por meio de dados em painel. O método de dados empilhados recebe recorrentemente diversas críticas pelo fato de desconsiderar os efeitos individuais dos países, o que gera problemas de viés. Os modelos obtidos com a adoção de dados em painel também têm sido objeto de críticas, já que também desconsideram as referidas características. A literatura, no entanto, demonstra que, quando se consideram os EF, torna-se possível ter mais controle sobre a heterogeneidade existente entre os países, ocasionada com base em diversos aspectos de natureza não observável (Arevalo et al., 2016).

De acordo com Gujarati (2006), o modelo pooled sinaliza para o comportamento uniforme de todos os indivíduos ao longo do tempo, de modo que todas as observações apresentam 
homogeneidade, em que se desconsideram os efeitos relacionados às unidades de seção cruzada, bem como o espaço temporal. Já no modelo de EF, genericamente, o intercepto varia entre as unidades analisadas, no entanto são constantes no decorrer do tempo, enquanto, no modelo de EA, tem-se que o intercepto de uma dada unidade consiste em elemento aleatório de um aglomerado maior, em que o intercepto reflete o valor médio de todos os interceptos de corte transversal.

Souza \& Burnquist (2011) salientam, ainda, que a utilização de EF, além de possibilitar o controle da heterocedasticidade dos países, capta o efeito de variáveis omitidas, seja por indisponibilidade de dados, seja por dificuldades de mensuração, como o caso dos índices de resistência multilateral. Já Cheng e Wall (2005) asseguram que o uso de EF também permite que se captem os efeitos dos custos comerciais bilaterais que não são diretamente observados, como o caso dos custos de transação, peculiaridades geográficas e contextos históricos específicos.

De acordo com Silva \& Tenreyro (2006), em diversas aplicações econométricas com esse enfoque, efetivam-se estimações e interpretações dos parâmetros por meio de modelos loglineares e, tendo em vista o método de mínimos quadrados ordinários, tal procedimento, no entanto, pode se equivocar quanto à existência de heterocedesticidade. Além disso, os autores afirmam que a falta de observações ou valores nulos pode problematizar a adoção da forma log-linear no modelo gravitacional. Desse modo, propuseram uma equação de gravidade estimada, em sua forma multiplicativa, com suporte no chamado PPML, haja vista que essa estimativa se adequa bem à ocorrência, tanto da heterocedasticidade como da nulidade de observações para a variável dependente. Para esses autores, a estimativa PPML tem melhor ajuste do que a de EF, já que não possui problemas de viés.

Portanto, seguindo os estudos de Souza \& Burnquist (2011), Pereira \& Almeida (2014) e Arevalo et al. (2016), foram considerados todos esses métodos anteriormente citados, sendo estimada a seguinte regressão:

$\operatorname{Ln}\left(\operatorname{Exp}_{\mathrm{ijt}}\right)=\alpha+\beta_{1} \operatorname{Ln}\left(\mathrm{Pibpc}_{-} \mathrm{x}_{\mathrm{it}}\right)+\beta_{2} \operatorname{Ln}\left(\mathrm{Pibpc}_{-} \mathrm{m}_{\mathrm{tj}}\right)+\beta_{3} \operatorname{Ln}\left(\operatorname{Dist}_{\mathrm{ij}}\right)+\beta_{4} \operatorname{Ln}\left(\mathrm{PI}_{\mathrm{t}}\right)+$ $\beta_{5} \operatorname{Ln}\left(I L C_{j t}\right)+\beta_{3} \operatorname{Ln}\left(\mathrm{TC}_{\mathrm{jt}}\right)+\mu_{\mathrm{ijt}}$

em que: $\operatorname{Exp}_{\mathrm{ijt}}$ refere-se aos valores das exportações brasileiras de mamão em dólares; Pibpc_ $\mathrm{x}_{\mathrm{it}}$ e Pibpc_ $\mathrm{m}_{\mathrm{tj}}$ representam, de forma respectiva, o PIB per capita nacional e o PIB per capita do país importador; Dist $t_{i j}$ diz respeito ao distanciamento geográfico entre o Brasil e os parceiros comerciais; $\mathrm{PI}_{\mathrm{t}}$ corresponde aos preços internacionais do mamão no mercado internacional; $\mathrm{ILC}_{\mathrm{jt}}$ indica o índice de liberdade comercial dos países importadores; $\mathrm{TC}_{\mathrm{jt}}$ trata-se da taxa de câmbio (US\$/R\$); $\mu_{\mathrm{ijt}}$ simboliza o erro estocástico.

A existência de efeitos individuais foi verificada por meio do teste do multiplicador de Lagrange de Breusch e Pagan, que procura testar a possibilidade de que a variância dos termos específicos seja nula, possibilitando a escolha entre os métodos com EA ou pooled. Ademais, também se empregou o teste de Hausman para analisar se os coeficientes se diferenciam de forma sistemática, o que torna possível a comparação entre os modelos com EF e EA. A hipótese nula do teste de Hausman sugere que o modelo com EA se adapta melhor do que o modelo com EF. Ressalta-se, ainda, a aplicação do teste de Chow, que realiza um comparativo da soma dos quadrados dos resíduos da regressão, estimada via modelo pooled, contra a soma dos quadrados dos resíduos da regressão por EF, sendo a preferência pelo modelo pooled a hipótese nula (Souza \& Burnquist, 2011).

Ademais, realizou-se a aplicação do teste de raiz unitária de Levin et al. (2002) para cada variável do painel de dados, a fim de verificar se as séries são estacionárias, haja vista que, de acordo com Machado et al. (2005), a não estacionariedade das séries do painel poderia gerar 
duas situações mutuamente excludentes: i) relação espúria na estimação obtida via utilização da metodologia convencional para dados em painel (Entorf, 1997); ii) aplicação única de um método de cointegração como meio de obter uma relação consistente entre as variáveis (Pedroni, 1999).

Além do problema anterior, Wooldridge (2010) indica que, atrelada às séries temporais, pode incidir a presença de autocorrelação, que ocorre quando não existe interdependência entre os erros de um mesmo indivíduo, mantendo correlação no decorrer do tempo. Portanto, buscando evitar esse problema, aplicou-se o teste de Wooldridge, que sugere, como hipótese nula, a ausência de correlação.

Segundo Gujarati (2006), embora o modelo de dados em painel tenha diversas vantagens ante outros modelos, pode apresentar, como limitação, outra dificuldade de estimação, que consiste na heterocedasticidade, uma vez que no modelo de dados em painel se realiza a junção de dados de corte transversal e séries temporais. Assim, também se realizou o teste Breusch-Pagan/Cook-Weisberg, para verificar se sua hipótese nula, de variância constante, é aceita ou recusada.

\section{Resultados e discussão}

Os resultados são apresentados nesta seção e foram subdivididos em duas partes. $\mathrm{Na}$ primeira, expõem-se as estatísticas descritivas das variáveis contempladas no modelo econométrico adotado no estudo e, na segunda, são expostos os resultados da estimação da equação gravitacional que se concentram no modelo PPML.

\subsection{Análise descritiva}

A priori, conforme já mencionado, realizou-se uma análise descritiva das variáveis consideradas na pesquisa como forma de resumir as principais características do conjunto de dados por meio do uso de medidas de dispersão (máximo, mínimo, desvio padrão e coeficiente de variação) e de tendência central ou de posição (média). Utilizou-se o período compreendido de 2002 a 2017 e consideraram-se os 21 países que representaram 99\% do total de importações do mamão no tempo anteriormente citado. Os resultados são expressos na Tabela 4.

Conforme se pode observar, no período considerado, os valores das exportações do mamão brasileiro variaram defluxos comerciais nulos, a US\$13.737.830,00, com média de US\$1.711.950, 00 e maior variabilidade no conjunto de variáveis, haja vista o mais elevado coeficiente de variação contido nessa variável (143,84\%). Considerando os países importadores de maneira desagregada, observou-se que o maior montante de exportação já mencionado foi direcionado à Holanda em 2005.

Tabela 4. Estatísticas descritivas das variáveis contempladas no estudo

\begin{tabular}{|c|c|c|c|c|c|}
\hline Variável & Mínimo & Média & Máximo & $\begin{array}{l}\text { Desvio } \\
\text { padrão }\end{array}$ & $\begin{array}{c}\text { Coeficiente } \\
\text { de } \\
\text { variação } \\
(\%)\end{array}$ \\
\hline $\begin{array}{l}\text { Exportações de mamão } \\
\text { (em mil US\$) }\end{array}$ & 0,00 & $1.711 .950,00$ & $13.737 .830,00$ & $2.462,42$ & 143,84 \\
\hline Distância geográfica (km) & 2.275 & 8.527 & 11.953 & $2.379,34$ & 27,90 \\
\hline $\begin{array}{l}\text { PIB per capita do Brasil } \\
\text { (em US\$) }\end{array}$ & $2.829,00$ & $8.360,00$ & $13.246,00$ & $3,377.04$ & 40,40 \\
\hline
\end{tabular}

Fonte: elaboração própria com base nos dados da pesquisa. 
Tabela 4. Continued...

\begin{tabular}{lccccc}
\multicolumn{1}{c}{ Variável } & Mínimo & Média & Máximo & $\begin{array}{c}\text { Coeficiente } \\
\text { de } \\
\text { Desvio } \\
\text { padrão }\end{array}$ & $\begin{array}{c}\text { variação } \\
\text { (\%) }\end{array}$ \\
$\begin{array}{l}\text { PIB per capita dos países } \\
\text { importadores (em US\$) }\end{array}$ & 111,10 & $35.529,00$ & $118.823,6$ & $23,426.54$ & 65,94 \\
$\begin{array}{l}\text { Preços internacionais do } \\
\text { mamão (US\$ por kg) }\end{array}$ & 0,59 & 1,10 & 1,67 & 0,31 & 28,01 \\
$\begin{array}{l}\text { Taxa de câmbio (US\$/R } \$ \text { ) } \\
\text { ILC }\end{array}$ & 0,02 & 0,81 & 2,00 & 0,54 & 65,89 \\
\hline
\end{tabular}

Fonte: elaboração própria com base nos dados da pesquisa.

Ao se tratar da renda per capita dos países que se relacionam comercialmente e tendo em vista o período considerado, verificou-se que, por um lado, a média do PIB per capita anual dos países selecionados para a amostra perfez um valor de US\$35.529,00, com destaque para Luxemburgo, que obteve o maior montante em 2014 (US\$118.823,6), e Etiópia, com a menor renda per capita (US\$111,10), em 2002. Ressalta-se, ainda, que a referida variável exibiu expressiva variabilidade em seus valores, sendo a segunda com maior dispersão no conjunto de variáveis, haja vista que seu coeficiente de variação foi de $65,94 \%$. Por outro lado, o PIB per capita do Brasil variou de US\$2.829,00 a US\$13.246,00 (2002 e 2017, respectivamente), com média de US\$ $\$ .360,00$ e relativa heterogeneidade, dado que seu coeficiente de variação foi de $40,40 \%$.

Além disso, evidenciou-se que a média da distância geográfica do Brasil perante seus parceiros comerciais foi de $8.527 \mathrm{~km}$, tendo variado aproximadamente $2.275 \mathrm{~km}$ (Brasil/Uruguai) a $11.953 \mathrm{~km}$ (Brasil/Emirados Árabes Unidos). O coeficiente de variação da distância geográfica encontra-se entre os três menores (27,90\%). Embora se considerem países da América do Sul, América do Norte, África e Ásia, o fato de parcela majoritária das exportações brasileiras de mamão ser direcionada para a Europa pode justificar essa reduzida variabilidade nos dados para a distância.

A média da taxa de câmbio, por sua vez, foi de US\$0,81 para cada real comprado pelo Banco Central. A maior e a menor taxa de câmbio do período foram de US\$0,02 e US\$2,00 para a Rússia, em 2003, e para o Reino Unido, em 2011, respectivamente. Já os preços do mamão no comercio internacional, medidos com base no quilograma do produto, variaram de US\$ 0,59 , em 2002, a US\$1,67, em 2014.

Por fim, salienta-se que o menor ILC foi o da Rússia, em 2008 (44,20), enquanto a Suíça, em 2010, foi o que obteve o maior índice $(90,0)$. Em média, os principais importadores do mamão brasileiro obtiveram um desempenho considerado majoritariamente livre, haja vista que o ILC médio observado foi de 80,83 . Essa foi a variável que apresentou a menor heterogeneidade nos dados, uma vez que expressou o menor coeficiente de variação (10,83\%).

\subsection{Análise do modelo gravitacional}

Antes de proceder à estimação do modelo gravitacional propriamente dito, aplicou-se o teste de raiz unitária de Levin et al. (2002) para cada variável considerada, como meio para observar se as séries são estacionárias e evitar o possível problema de regressão espúria, mencionado na seção metodológica. Ressalta-se que as variáveis adotadas para a análise do desempenho exportador do mamão brasileiro no comércio internacional foram estimadas na sua forma de logaritmo natural, visando à captação do efeito da elasticidade pelos respectivos coeficientes. Os resultados do referido teste são expostos na Tabela 5. 
Tabela 5. Teste de Levin et al. (2002) de raiz unitária para as variáveis consideradas no modelo gravitacional

\begin{tabular}{lccc}
\multicolumn{1}{c}{ Variável } & Ordem de integração & Estatística do teste & P-valor \\
Exportações de mamão & $I(0)$ & -4.2830 & 0,0000 \\
LnPIBpcj & $I(0)$ & -4.9853 & 0,0000 \\
LnPIBpci & $I(0)$ & -2.4467 & 0,0072 \\
LnILN & $I(0)$ & -7.5057 & 0,0000 \\
LnPI & $I(0)$ & -9.2384 & 0,0000 \\
LnTC & $I(0)$ & -4.5142 & 0,0000 \\
\hline
\end{tabular}

Fonte: elaboração própria com base nos dados contemplados na pesquisa.

Como pode ser observado, com base nos resultados do teste, ao nível de 1\% de significância, pode-se rejeitar a hipótese nula de que há raiz unitária para todas as séries, sendo elas, portanto, estacionárias em nível. Assim, torna-se possível prosseguir com o procedimento metodológico, que consiste na estimação dos determinantes das exportações do mamão brasileiro, sem incorrer nos problemas anteriormente mencionados.

Como já delineada na seção metodológica, a estimação do modelo gravitacional foi realizada via modelos pooled, EF, EA e PPML. Salienta-se que, como nos estudos de Andia et al. (2011), Silva (2015) e Mazzuchetti \& Shikida (2017), também foram realizados os testes de Breusch Pagan e Cook/ Weisberg \& Wooldridge para verificar a presença de heterocedasticidade e autocorrelação, respectivamente, bem como a aplicação dos testes de Chow, multiplicador de Lagrange (LM) de Breusch-Pagan e Hausman para a escolha do método mais adequado de estimação. Os resultados desses testes, em que são indicadas as hipóteses nulas e alternativas, são expostos na Tabela 6.

Tabela 6. Estatísticas dos testes de hipóteses

\begin{tabular}{llll}
\multicolumn{1}{c}{ Teste } & \multicolumn{1}{c}{ Tipo de análise } & \multicolumn{1}{c}{ Hipótese nula } & P-valor \\
Breusch-Pagan/Cook-Weisberg & Heterocedasticidade & Homocedasticidade & 0,0000 \\
Wooldridge & Correlação serial & Ausência de autocorrelação & 0,0000 \\
Chow & Pooled $x$ EF & Modelo pooled & 0,0000 \\
LM de Breusch-Pagan & Pooled $x$ EA & Modelo pooled & 0,0000 \\
Hausman & EF $x$ EA & Modelo de EA & 0,6832 \\
\hline
\end{tabular}

Fonte: elaboração própria com base nos resultados da pesquisa.

Conforme se pode verificar, o teste de heterocedasticidade de Breusch-Pagan/Cook Weisberg sugere a presença de heterocedasticidade, haja vista que a hipótese de variância constante foi rejeitada a $1 \%$ de significância. Já o teste de Woodridge revela que existem indícios de correlação serial, uma vez que a hipótese nula de ausência de autocorrelação também foi rejeitada a 1\% de significância. Com efeito, a fim de corrigir os referidos problemas, tornou-se necessária a estimação do modelo gravitacional, levando-se em consideração os erros-padrão robustos como meio de atenuar a incidência dos referidos pressupostos, realizando-se também sua clusterização.

$\mathrm{O}$ teste de Chow, que realiza o comparativo entre o modelo pooled e o de $\mathrm{EF}$, indicou, ao nível de $1 \%$ de significância, que a hipótese nula de que não há heterogeneidade entre os grupos de indivíduos no painel deve ser rejeitada, evidenciando a preferência do modelo de EF perante o modelo de dados empilhados (pooled).

Já o teste multiplicador de Lagrange (LM) de Breusch-Pagan, que analisa os resíduos de modelo estimado por meio de mínimos quadrados ordinários, possibilita analisar a estimação 
mais satisfatória entre os modelos pooled e EA, sugeriu que a variação (u) é diferente de zero, portanto a hipótese nula de que não existem EA foi rejeitada a $1 \%$ de significância, indicando que o modelo de EA seria mais apropriado do que o pooled.

Por fim, o teste de Hausman, útil na tomada de decisão entre o modelo de EF ou aleatórios, rejeitou a hipótese nula de erros não sistemáticos para o modelo, sendo preferível, nesse caso, o modelo de EA ante o modelo de EF, dada a não significância do teste de Hausman. A estimativa realizada por EA é mais indicada nesse caso, haja vista que, segundo Maddala (2001), a técnica de dados em painel para o modelo gravitacional, que tem a distância como variável tradicional, e a possível inclusão de variáveis binárias, caracterizadas por serem constantes entre as unidades cross-sections, deve utilizar, preferencialmente, a estimação por EA.

Nesse sentido, seguindo os estudos de Arevalo et al. (2016) e Agudelo (2017) e considerando as vantagens e desvantagens desses modelos e abordagem teórica do modelo gravitacional, optou-se por apresentar os resultados para todos esses modelos, com destaque para a inclusão do modelo PPML, já que, segundo Silva \& Tenreyro (2006), tal modelo não produziu estimativas viesadas em suas simulações de Monte Carlo, considerando os efeitos individuais dos países, sendo mais robusto do que os demais modelos, inclusive na presença de heterocedasticidade. Os resultados são expostos na Tabela 7.

Conforme pode ser verificado, no caso do modelo pooled, o PIB per capita, tanto do Brasil quanto dos países importadores, o ILC e a ausência de litoral não foram significativos. Consoante assinala Weeks (2014), no entanto, dado que a variância não é nula, fato demonstrado pelo teste LM de Breusch-Pagan, seus resultados podem ser descartados. No modelo de EA, apenas a distância e as variáveis referentes aos blocos econômicos foram significativas estatisticamente. No caso do modelo de EF, as variáveis não apresentaram significância e convém destacar nesse caso, entretanto, que as variáveis representantes da distância, dos blocos econômicos e ausência de litoral foram omitidas por serem invariantes no tempo.

Como mencionado anteriormente, Silva \& Tenreyro (2006) sinalizam que o modelo PPML possui robustez mais elevada, argumento ratificado por Weeks (2014), sendo, portanto, o modelo com os coeficientes analisados.

Desse modo, com base na Tabela 7, nota-se que, ao nível de 1\% de significância, o aumento de $1 \%$ na distância entre o Brasil e seus parceiros comerciais tende a reduzir o fluxo bilateral entre eles em aproximadamente $6 \%$. O resultado está de acordo com o preconizado pela literatura, haja vista que, conforme Silva (2015) e Arevalo et al. (2016), tal variável consiste em um obstáculo ao comércio entre os países, já que pode ensejar custos de transportes expressivos, causando desestímulo às importações do produto em questão.

Tabela 7. Estimativas do modelo gravitacional para os modelos pooled, EF, EA e PPML

$\begin{array}{lcccc} & \text { Pooled } & \text { EF } & \text { EA } & \text { PPML } \\ \text { Lndist } & -10,9655^{\star * *} & 0,0000 & -14,7173^{* * *} & -5,9483^{* * *} \\ & (3,2087) & (.) & (2,4964) & (1,7957) \\ \text { LnPIBpci } & & & \\ & -0,5133 & -0,3158 & -0,2314 & -0,5401 \\ & (0,5193) & (0,5472) & (0,5240) & (0,4121) \\ \text { LnPIBpcj } & & & \\ & 0,4073 & 0,6956 & 0,3016 & 1,0750^{*} \\ & (0,6736) & (0,4210) & (0,3355) & (0,6498)\end{array}$

Nota: entre parênteses encontram-se os erros padrão. Os valores do $\mathrm{R}^{2}$ dos modelos de EF e EA dizem respeito à classe between groups. * Reflete significância a 10\%; **: significância a 5\%; ***: significância a 1\%. Fonte: elaboração própria com base nos resultados da pesquisa. 
Tabela 7. Continued...

\begin{tabular}{|c|c|c|c|c|}
\hline & Pooled & EF & EA & PPML \\
\hline LnPI & $\begin{array}{c}1,8159 * \\
(1,0152)\end{array}$ & $\begin{array}{c}1,4293 \\
(1,1315)\end{array}$ & $\begin{array}{c}1,4352 \\
(1,0888)\end{array}$ & $\begin{array}{l}0,6599 * * \\
(0,2911)\end{array}$ \\
\hline $\operatorname{Ln} T C$ & $\begin{array}{l}0,7626 * \\
(0,4122)\end{array}$ & $\begin{array}{c}0,3275 \\
(0,4379)\end{array}$ & $\begin{array}{c}0,3349 \\
(0,3282)\end{array}$ & $\begin{array}{l}1,0799 * * * \\
(0,3543)\end{array}$ \\
\hline LnILC & $\begin{array}{c}4,4395 \\
(4,0525)\end{array}$ & $\begin{array}{c}3,6585 \\
(2,9512)\end{array}$ & $\begin{array}{c}3,9597 \\
(2,7926)\end{array}$ & $\begin{array}{l}6,4650 * * * \\
(2,2128)\end{array}$ \\
\hline Sem_litoral & $\begin{array}{l}-1,8050 \\
(1,2524)\end{array}$ & $\begin{array}{l}0,0000 \\
(.)\end{array}$ & $\begin{array}{l}-1,3481 \\
(1,0738)\end{array}$ & $\begin{array}{l}-2,1899 * * \\
(1,0045)\end{array}$ \\
\hline Mercosul & $\begin{array}{c}-13,8838 * * * \\
(4,8630)\end{array}$ & $\begin{array}{l}0,0000 \\
(.)\end{array}$ & $\begin{array}{c}-19,7272 * \star * \\
(3,8785)\end{array}$ & $\begin{array}{l}-5,7467 * * \\
(2,5019)\end{array}$ \\
\hline Nafta & $\begin{array}{l}-2,0588 * * \\
(0,8355)\end{array}$ & $\begin{array}{l}0,0000 \\
(.)\end{array}$ & $\begin{array}{l}-2,4701 * * * \\
(0,8203)\end{array}$ & $\begin{array}{l}-1,3529 * * \\
(0,6771)\end{array}$ \\
\hline _cons & $\begin{array}{l}169,8085^{* * *} \\
(58,0863)\end{array}$ & $\begin{array}{l}-7,1746 \\
(9,1746)\end{array}$ & $\begin{array}{c}230,1359 * * * \\
(38,1933)\end{array}$ & $\begin{array}{l}74,5023 * * \\
(31,1181)\end{array}$ \\
\hline $\mathrm{N}$ & 240 & 240 & 240 & 336 \\
\hline $\begin{array}{l}\mathrm{R}^{2} \\
\text { Reset }\end{array}$ & 0,57 & 0,21 & 0,67 & $\begin{array}{l}0,51 \\
0,26\end{array}$ \\
\hline
\end{tabular}

Nota: entre parênteses encontram-se os erros padrão. Os valores do $\mathrm{R}^{2}$ dos modelos de EF e EA dizem respeito à classe between groups. * Reflete significância a 10\%; **: significância a 5\%; ***: significância a 1\%. Fonte: elaboração própria com base nos resultados da pesquisa.

No que diz respeito ao coeficiente do PIB per capita dos países importadores, evidenciou-se relação positiva e significativa com o nível de $10 \%$ de significância das exportações do mamão brasileiro. Assim, o acréscimo de 1\% na renda per capita dos parceiros comerciais brasileiros leva a uma variação positiva de 1,07\% nas exportações do referido produto nacional. Essa evidência é pertinente ao que é mostrado pela teoria, em que a renda e a demanda mantêm uma relação direta, podendo ser citados os estudos de Zanchi (2010), Souza \& Burnquist (2011), Scheltema (2018), Silva (2015) e Arevalo et al. (2016). Quanto ao PIB per capita brasileiro, nada se pode inferir acerca de seu impacto sobre as exportações do mamão brasileiro, uma vez que seu coeficiente foi o único insignificante no conjunto de variáveis adotadas.

Já a variável que reflete os preços internacionais do mamão demonstrou significância a $5 \%$, apresentando relação diretamente proporcional às exportações brasileiras de mamão. Assim, o crescimento de $1 \%$ nos preços internacionais desse produto leva a um aumento de $0,66 \%$ nas suas exportações nacionais. Esse resultado condiz com o esperado, na medida em que a elevação dos preços internacionais do mamão pode tornar o mamão brasileiro mais atrativo. Essa inferência corrobora as pesquisas de Fonseca et al. (2010) e Arevalo et al. (2016) ao indicar que o crescimento do preço internacional, respectivamente, da uva fresca e do café proporciona elevação nos seus valores de exportação.

A taxa de câmbio também obteve significância estatística e relação positiva com as exportações de mamão brasileiro. Dessa forma, o aumento de $1 \%$ na taxa de câmbio gera variações positivas de aproximadamente 1,08\% nas exportações de mamão, resultado que segue o apresentado pela literatura. Ressalta-se que como se utilizou a taxa de câmbio dos países importadores 
ante o real, o aumento da taxa de câmbio, nesse caso, representa a valorização da moeda do país de destino do mamão brasileiro ante o real. Arevalo et al. (2016) justificam essa evidência, afirmando que desvalorizações na moeda nacional de um determinado país tendem a incentivar suas exportações, o que é o caso do Brasil. Ao se tratar do ILC dos importadores brasileiros selecionados, evidencia-se que o aumento de $1 \%$ na liberdade comercial dos parceiros comerciais brasileiros proporciona o crescimento de $6,46 \%$, resultado com respaldo no estudo de Aguiar (2018).

Com relação às variáveis binárias que indicam a qual bloco econômico pertencem os países importadores, verificaram-se que, em todos os modelos analisados, dadas as significâncias em suas estimativas, os países pertencentes ao Mercosul e ao Tratado Norte-Americano de Livre Comércio (North American Free Trade Agreement) (Nafta) apresentaram desempenhos inferiores quando comparados aos de países pertencentes ao bloco que contempla os países europeus. Por um lado, no caso do Mercosul, pode-se justificar esse resultado, conforme Ferreira et al. (2010), que sugerem que a renda e a dotação de fatores de produção conduzem a um reduzido comércio de frutas intrabloco, haja vista que, embora as frutas possam ser comercializadas in natura, expressam elevado valor agregado, especialmente em razão de aspectos de logística e qualidade. Assim, dado que os países pertencentes ao Mercosul possuem, em média, rendas per capita inferiores às dos países da União Europeia, o consumo de frutas nesses países é relativamente menor. Por outro lado, tratando-se do Nafta, tal resultado pode ser explicado pelas maiores exigências sanitária, fitossanitária e técnica dos países que compõem esse bloco. De acordo com Ferreira et al. (2010), entre 1995 e 2008, o Nafta emitiu duas vezes mais notificações sobre medidas sanitárias e fitossanitárias, bem como de barreiras comerciais, do que os países da União Europeia. As barreiras são divididas em dois grupos: as tarifárias (tarifas de importação, por exemplo) e as não tarifárias, como direitos antidumping, impostos de compensação, subsídios, padrões de qualidade etc.

Além disso, tem-se que a variável dummy relacionada ao fato de o país importador possuir ou não saída para o mar também foi significativa, resultado condizente com o esperado na literatura, a exemplo do estudo de Silva (2015), indicando que a existência de saída para o oceano contribui positivamente nos fluxos comerciais entre o Brasil e seus parceiros comerciais.

Por fim, pode-se observar que o percentual de $51,50 \%$ da variação da exportação do mamão brasileiro está sendo explicado pelo conjunto adotado de variáveis independentes. O baixo $R^{2}$ verificado, segundo Arevalo et al. (2016), pode ter sido consequência da seleção dos mercados de destino. No entanto, como forma de comprovar que o modelo empregado é apropriado, aplicou-se o teste de Reset, de Ramsey (1969), em que a hipótese nula de que o modelo não apresenta variáveis omitidas não pode ser rejeitada. Em virtude da não rejeição dessa hipótese, evidencia-se que o modelo empregado não contém erros de especificação.

\section{Considerações finais}

Como se pode observar, o Brasil detém papel de destaque no comércio internacional de mamão, estando entre os principais produtores e exportadores dessa fruta. De 2002 a 2017, o mamão foi responsável por gerar cerca de 550 milhões de dólares, advindos predominantemente da Europa e dos Estados Unidos, que, juntos, correspondem a aproximadamente $90 \%$ desse montante.

Este artigo, com efeito, teve o propósito de analisar os determinantes das exportações brasileiras de mamão, considerando países da Europa, da América do Sul e da América do Norte, que representaram quase $99 \%$ do total de exportações da referida fruta de 2002 a 
2017. Para tanto, aplicou-se o modelo gravitacional, que passa pela aplicação da metodologia de dados em painel.

Na estimação da equação gravitacional aplicada ao mamão, procurou-se analisar o impacto de variáveis identificadas na teoria como relevantes para qualquer que seja o fluxo comercial, quais sejam: a renda do exportador e a dos países importadores, o distanciamento geográfico entre o Brasil e seus parceiros comerciais, os preços internacionais do mamão, a taxa de câmbio e um indicador de liberdade econômico, além de variáveis binárias que representaram o bloco econômico de que o país importador faz parte e se o país em questão possui algum território litorâneo.

Os resultados demonstraram que, assim como para outros fluxos comerciais de outros produtos, tais variáveis são importantes condicionantes das exportações do mamão brasileiro, com exceção do ILC, e da renda nacional, tendo mostrado sinais condizentes com o preconizado pela literatura. Desse modo, observou-se, de fato, no caso do mamão, que seus fluxos no comércio são explicados diretamente pelo tamanho econômico de seus parceiros comerciais e inversa e proporcionalmente à distância que separam o mercado de origem dos mercados de destino. Além disso, pode-se destacar a relação direta das exportações do mamão brasileiro com os preços internacionais e a taxa de câmbio.

Ademais, ressalta-se o menor desempenho de países do Mercosul e do Nafta em relação às exportações do mamão brasileiro, justificado pela menor renda per capita e dotação de fatores dos países do Mercosul perante os países da União Europeia, e das imposições fitossanitárias, no caso dos países do Nafta.

\section{Referências}

Abidin, I. S. Z., Haseeb, M., Chiat, L. W., \& Islam, M. R. (2016). Determinants of Malaysia-BRICS trade linkages: gravity model approach. Investment Management and Financial Innovations, 13(2), 389-398.

Agudelo, A. M. A. (2017). Impactos da volatilidade da taxa de câmbio de cambio no comércio da Colômbia com seus principais parceiros comerciais mediante um modelo gravitacional período 2004-2014 (Dissertação de mestrado). Universidade Federal do Paraná, Curitiba.

Aguiar, G. M. B. (2018). Condicionantes da exportação de carne bovina do Brasil: uma abordagem gravitacional (Dissertação de mestrado). Universidade Federal do Ceará, Fortaleza.

Ahmed, J., Shivhare, U. S., \& Sandhu, K. S. (2002). Thermal degradation kinetics of carotenoids and visual color of papaya puree. Journal of Food Science, 67(7), 2692-2695.

Almeida, F. M. D., Silva, O. M. D., \& Braga, M. J. (2011). O comércio internacional do café brasileiro: a influência dos custos de transporte. Revista de Economia e Sociologia Rural, 49(2), 323-340.

Anderson, J. E. (1979). A theoretical foundation for the gravity equation. The American Economic Review, 69(1), 106-116.

Anderson, J. E., \& Wincoop, E. (2003). Gravity with gravitas: a solution to the border puzzle. The American Economic Review, 93(1), 170-192.

Anderson, J. E., \& Wincoop, E. (2004). Trade costs. Journal of Economic Literature, 42(3), 691-751.

Andia, L. H., Garcia, R., \& Bacha, C. J. C. (2011). A influência dos fatores econômicos e jurídicos sobre o desempenho das empresas do agronegócio brasileiro: período de 2003 a 2005. Revista de Economia e Sociologia Rural, 49(4), 875-908.

Anibijuwon, I. I., \& Udeze, A. O. (2009). Antimicrobial activity of Carica papaya (pawpaw leaf) on some pathogenic organisms of clinical origin from South-Western Nigeria. Ethnobotanical Leaflets, 2009(7), 4. 
Arevalo, J. L. S., Andrade, Á. M. F. D., \& Silva, G. A. B. (2016). Uma nota sobre modelos gravitacionais aplicados à exportação de café de Brasil, Colômbia e Peru. Revista Brasileira de Economia, 70(3), 271-280.

Bampi, S. L. (2017). Uma abordagem gravitacional da evolução do comércio potencial entre o Brasil e parceiros asiáticos selecionados (Dissertação de mestrado). Universidade do Vale do Rio dos Sinos, São Leopoldo.

Bergstrand, J. H. (1985). The gravity equation in international trade: some microeconomic foundations and empirical evidence. The Review of Economics and Statistics, 67(3), 474-481.

Bergstrand, J. H. (1990). The Heckscher-Ohlin-Samuelson model, the Linder hypothesis and the determinants of bilateral intra-industry trade. Economic Journal (London), 100(403), 1216-1229.

Brasil. (2018). Ministério do Desenvolvimento, Indústria e Comércio Exterior - MDIC. Estatísticas de Comércio Exterior do Brasil. Brasília: MDIC. Recuperado em 10 de outubro de 2018, de http://comexstat.mdic.gov.br/pt/home

Cardoso, R. D., Schneider, M. B., \& Bechlin, A. R. (2016). Desenvolvimento do Mercosul: uma avaliação dos fluxos de comércio. Redes, 21(1), 9-35.

Centre d'Estudes Prospectives et d'Intertionales Distances - CEPII. The GeoDist database. 2021. Recuperado em 20 de maio de 2021, de https://x.gd/OADos.

Cheng, I. H., \& Wall, H. J. (2005). Controlling for heterogeneity in gravity models of trade integration. Federal Reserve Bank of St. Louis Review, 87(1), 49-63.

Deardorff, A. V. (1998). Determinants of bilateral trade: does gravity work. In J. A. Frankel (Ed.), The regionalization of the world economy (pp. 7-22). Chicago: University of Chicago Press.

Egger, P., \& Pfaffermayr, M. (2004). Distance, trade and FDI: a Hausman-Taylor SUR approach. Journal of Applied Econometrics, 19(2), 227-246.

Entorf, H. (1997). Random walks with drifts: nonsense regression and spurious fixed-effect estimation. Journal of Econometrics, 80(2), 287-296.

Fachinello, J. C., Pasa, M. D. S., Schmtiz, J. D., \& Betemps, D. L. (2011). Situation and perspectives of temperate fruit crops in Brazil. Revista Brasileira de Fruticultura, 33(spe 1), 109-120.

Fackler, P. L., \& Goodwin, B. K. (2001). Spatial price analysis. Handbook of Agricultural Economics, $1,971-1024$

Faria, R. N., Souza, R. C., Vieira, J. G. V., \& Lírio, V. S. (2008). Custo de transação e exigências técnicas nas exportações de manga e de mamão. Informações Econômicas, 38(5), 59-71.

Farias, J. J. D., \& Hidalgo, A. B. (2012). Comércio interestadual e comércio internacional das regiões brasileiras: uma análise utilizando o modelo gravitacional. Revista Economica do Nordeste, 43(2), 251-265.

Feenstra, R. C., Markusen, J. R., \& Rose, A. K. (2001). Using the gravity equation to differentiate among alternative theories of trade. The Canadian Journal of Economics. Revue Canadienne d'Economique, 34(2), 430-447.

Ferreira, M. D. P., Lírio, V. S., \& Mendonça, T. G. (2010). Análise do perfil e grau de incidência de barreiras não-tarifárias sobre as exportações brasileiras de frutas selecionadas. Revista Economica do Nordeste, 41(4), 683-698.

Fonseca, H. V. P., Xavier, L. F., \& Costa, E. F. (2010). Análise das exportações de uvas frescas brasileiras: uma estimação gravitacional a partir do modelo de regressões aparentemente não relacionadas. Revista de Economia Agrícola, São Paulo, 57(2), 81-98. 
Food and Agriculture Organization of the United Nations - FAOSTAT. (2018). Culturas e produtos pecuários. Recuperado em 19 de maio de 2018, de http://faostat.fao.org/

Fratianni, M. (2009). The gravity model in international trade. In A. M. Rugman (Ed.), The Oxford handbook of international business (pp. 72-89). Oxford: Oxford University Press.

Gräf, C. O., \& Azevedo, A. F. Z. D. (2013). Comércio bilateral entre os países membros do MERCOSUL: uma visão do bloco através do modelo gravitacional. Economia Aplicada, 17(1), 135-158.

Gujarati, D. (2006). Econometria básica. São Paulo: Elsevier.

Hardisson, A., Rubio, C., Baez, A., Martin, M. M., \& Alvarez, R. (2001). Mineral composition of the papaya (Carica papaya variety sunrise) from Tenerife island. European Food Research and Technology, 212(2), 175-181.

Helliwell, J. F. (1997). National borders, trade and migration. Pacific Economic Review, 2(3), 165-185.

Helpman, E., \& Krugman, P. (1985). Market structure and foreign trade Cambridge (pp. 959973). Cambridge: MIT Press.

Hidalgo, A. B., \& Vergolino, J. R. (1998). O Nordeste e o comércio inter-regional e internacional: um teste dos impactos por meio do modelo gravitacional. Economia Aplicada, 2(4), 707-725.

Instituto Brasileiro de Geografia e Estatística - IBGE. (2020). Produção Agrícola Municipal. Recuperado em 05 de julho de 2020, de https://sidra.ibge.gov.br/pesquisa/pam/tabelas

Kist, B. B., Santos, C. E., Carvalho, C., \& Beling, R. R. (2018). Anuário brasileiro de horti \& fruti 2019. Santa Cruz do Sul: Editora Gazeta Santa Cruz.

Kristjánsdóttir, H. (2005). A gravity model for exports from Iceland. Dinamarca: Centre for Applied Microeconometrics, Department of Economics, University of Copenhagen. Recuperado em 20 de maio de 2018, de https://www.econ.ku.dk/cam/wp0910/wp0406/2005-14.pdf

Jaime, P. C., Figueiredo, I. C. R., Moura, E. C., \& Malta, D. M. (2009). Fatores associados ao consumo de frutas e hortaliças no Brasil, 2006. Revista de Saúde Pública, São Paulo, 43, 57-64.

Krugman, P. (1980). Scale economies, product differentiation, and the pattern of trade. The American Economic Review, 70(5), 950-959.

Krugman, P. R., \& Obstfeld, M. (2010). Economia Internacional(8th ed.). São Paulo: Makron Books.

Leusin Júnior, S., \& Azevedo, A. F. Z. D. (2009). O efeito fronteira das regiões brasileiras: uma aplicação do modelo gravitacional. Revista de Economia Contemporânea, 13(2), 229-258.

Levin, A., Lin, C. F., \& Chu, C. S. J. (2002). Unit root tests in panel data: asymptotic and finitesample properties. Journal of Econometrics, 108(1), 1-24.

Linnemann, H. (1966). An econometric study of international trade flows (No. 42). Amsterdam: North-Holland Publishing.

Machado, J. B. D. B., Sachsida, A., \& Mendonça, M. J. C. D. (2005). Abertura comercial e inflação: uma análise para dados em painel. Estudos Econômicos (São Paulo), 35(3), 547-567.

Maddala, G. S. (2001). Introdução à econometria. Rio de Janeiro: LTC - Livros Técnicos e Científicos.

Mata, D. D., \& Freitas, R. E. (2008). Produtos agropecuários: para quem exportar? Revista de Economia e Sociologia Rural, 46(2), 257-290.

Mazzuchetti, R. N., \& Shikida, P. F. (2017). O comércio internacional do açúcar sob a perspectiva do modelo gravitacional. Revista de Ciências Agrárias (Belém), 40(2), 210-220. 
Nakasone, H. Y., \& Paull, R. E. Papaya. In: R. E. PAULL \& O. DUARTE, (Orgs.). Tropical Fruits. New York: CAB International, 1998. p. 291-327.

Paula, J. S., \& Miranda, M. I. C. (2017). Análise do padrão de comércio entre os países do BRICS. Ensaios FEE, 37(4), 1005-1032.

Pedroni, P. (1999). Critical values for cointegration tests in heterogeneous panels with multiple regressors. Oxford Bulletin of Economics and Statistics, 61(S1), 653-670.

Pereira, F. O., \& Almeida, A. N. (2014). O impacto das medidas técnicas sobre as exportações brasileiras de papel e celulose. Revista de Economia e Agronegócio, 12(1-3), 3-22.

Porto, P. C., \& Canuto, O. (2004). Uma avaliação dos impactos regionais do Mercosul usando dados em painel. Pesquisa e Planejamento Economico, 34(3), 465-484.

Poyhonen, P. (1963). A tentative model for the volume of trade between countries. Weltwirtschaftliches Archiv, 90, 93-100.

Prates, R. C., \& Pereira, H. P. (2015). Análise dos fatores determinantes do comércio internacional brasileiro: uma análise do modelo gravitacional. Reflexões Econômicas, 1(1), 105-129.

Ramsey, J. B. (1969). Tests for specification errors in classical linear least $\square$ squares regression analysis. Journal of the Royal Statistical Society. Series B. Methodological, 31(2), 350-371.

Scheltema, N. (2018). A gravity approach to the determinants of international bovine meat trade (Dissertação de mestrado). University of Pretoria, Pretoria.

Serrano, L. A. L., \& Cattaneo, L. F. (2010). O cultivo do mamoeiro no Brasil. Revista Brasileira de Fruticultura, 32(3)

Silva, J. R. P. (2017). Exportações brasileiras - aplicação do Modelo Gravitacional (Dissertação de mestrado). Instituto Superior de Contabilidade e Administração do Porto, Porto.

Silva, J. S., \& Tenreyro, S. (2006). The log of gravity. The Review of Economics and Statistics, 88(4), 641-658.

Silva, O. M. D., \& Almeida, F. M. D. (2009). O viés doméstico no comércio interestadual de produtos florestais no Brasil. Revista Árvore, 33(2), 367-375.

Silva, T. J. (2015). Desempenho exportador da manga e da uva brasileira no comércio internacional: uma análise entre o período de 2003 a 2013 (Dissertação de mestrado). Universidade Federal de Pernambuco, Recife.

Soares, N. S., \& Silva, M. L. D. (2011). Oferta de exportação da celulose brasileira. Revista de Política Agrícola, 20(2), 52-65.

Souza, M. J. P. D., \& Burnquist, H. L. (2011). Facilitação de comércio e impactos sobre o comércio bilateral. Estudos Econômicos, 41(1), 91-118.

Tinbergen, J. (1962). Shaping the world economy. suggestions for an international economic policy. New York: Twentieth Century Fund.

Tansakul, A., Kantrong, H., Saengrayup, R., \& Sura, P. (2012). Thermophysical properties of papaya puree. International Journal of Food Properties, 15(5), 1086-1100.

Tomich, F. A. (1999). Competitividade das exportações brasileiras de frutas selecionadas. (Tese de doutorado em Economia Rural). Universidade Federal de Viçosa, Viçosa.

Vitti, A. (2009). Análise da competitividade das exportações brasileiras de frutas selecionadas no mercado internacional. (Dissertação de mestrado em Economia Aplicada). Universidade de São Paulo, São Paulo. 
Wall, M. M. (2006). Ascorbic acid, vitamin A, and mineral composition of banana (Musa sp.) and papaya (Carica papaya) cultivars grown in Hawaii. Journal of Food Composition and Analysis, 19(5), 434-445.

Weeks, D. V. (2014). Determinantes do investimento estrangeiro direto bilateral: uma abordagem do ambiente de negócios (Tese de doutorado). Escola Superior de Agricultura "Luiz de Queiroz" - ESALQ, Universidade de São Paulo, Piracicaba.

Wooldridge, J. M. (2010). Econometric analysis of cross section and panel data. Cambridge: MIT press.

Zanchi, V. V. (2010). Determinantes das exportações brasileiras de frutas frescas in natura: uma abordagem sob a ótica do modelo gravitacional (Dissertação de Mestrado). Universidade Federal do Pernambuco, Recife.

Zanchi, V. V., Farias, É. C., Schwantes, F., \& Xavier, L. F. (2013). Desempenho das exportações brasileiras de frutas in natura (1996-2007): uma análise sob a ótica do modelo gravitacional. Revista Teoria e Evidência Econômica, 19(41), 9-34.

Zhu, L., \& Yang, J. (2008). The role of psychic distance in contagion: a gravity model for contagious financial crises. Journal of Behavioral Finance, 9(4), 209-223.

Data de submissão: 22 de abril de 2019

Data de aceite: 18 de dezembro de 2020

JEL Classification: F13, Q17. 


\section{Apêndice}

Tabela 1A. Países e cidades principais utilizadas no cálculo da distância

\begin{tabular}{llc} 
& \multicolumn{1}{c}{ Cidade principal } & Distância (em km) \\
Argentina & Buenos Aires & 2344,93 \\
Áustria & Viena & 9511,48 \\
Bélgica & Bruxelas & 8957,62 \\
Canadá & Toronto & 7319,65 \\
Dinamarca & Copenhage & 9717,87 \\
Etiópia & Addis Ababa & 9942,82 \\
França & Paris & 8705,79 \\
Alemanha & Berlim & 9576,57 \\
Itália & Roma & 8891,16 \\
Luxemburgo & Luxemburgo & 8972,55 \\
Holanda & Amsterdã & 9093,93 \\
Polônia & Varsóvia & 10012,65 \\
Portugal & Lisboa & 7261,13 \\
Rússia & Moscou & 11171,51 \\
Arábia Saudita & Riad & 11193,93 \\
Espanha & Madri & 7717,90 \\
Suíça & Berna & 8871,11 \\
Emirados Árabes Unidos & Abu Dhabi & 11950,61 \\
Reino Unido & Londres & 8769,56 \\
Estados Unidos & Nova York & 6814,15 \\
Uruguai & Montevidéu & 2274,73 \\
\hline
\end{tabular}

Fonte: Centro de Pesquisa Francês no Âmbito da Economia Internacional (Centre d'Estudes Prospectives et d'Intertionales Distances, 2021). 